\title{
EMPIRICAL EVIDENCE OF ENTREPRENEURIAL COMPETENCIES AND FIRM PERFORMANCE: A STUDY OF WOMEN ENTREPRENEURS OF NIGERIA
}

\author{
Kabir MOHAMMED \\ School of Management, Universiti Sains Malaysia \\ Hazril Izwar IBRAHIM \\ School of Management, Universiti Sains Malaysia \\ Khairul Anuar MOHAMMAD SHAH \\ School of Management, Universiti Sains Malaysia
}

\begin{abstract}
The purpose of current study is to investigate the effects of entrepreneurial competencies on firm performance of businesses owned by Nigerian women entrepreneurs. The 200 respondents of this study are women entrepreneurs operating micro-business units in Kaduna state, Nigeria. Survey questions was used to collect data. The study utilises SPSS and SmartPLS 2.0 to analyse the data. The findings indicated that strategic, opportunity and organizing competencies significantly affect the firm performance of women entrepreneurs in Nigeria.
\end{abstract}

\section{KEYWORDS}

strategic competency, opportunity competency, organizing competency, women entrepreneurs, , firm performance.

\section{JEL CLASSIFICATION}

$M 13$

\section{INTRODUCTION}

Entrepreneurs has been gaining more interest in recent years due to its' ability to create jobs, alleviate poverty and as innovator to new goods and services (Adesua-Lincoln, 2012). According to Cohoon, Wadhwa, and Mitchell (2010) entrepreneurship, enables societal and economic transformation by providing the community with wealth. Thus, with such importance attached to entrepreneurship, there is an urgent need to investigate the type of competencies required to make entrepreneurial endeavour a success.

Competencies of the entrepreneurs are one of the significant determining factor for success, performance and growth or failure of business operation (Brinckmann, 2008; Kiggundu, 2002; Mitchelmore \& Rowley, 2013). Furthermore, women entrepreneurs mostly operate small scale type of businesses which requires the businesses to depend mainly on the competencies of the owner. Thus, understanding the nature of such competencies in the context of women entrepreneurs is very important (Mitchelmore \& Rowley, 2010; Mitchelmore, Rowley, \& Shiu, 2014). 
However, female led businesses in Nigeria like their counterpart in other parts of the world face numerous business challenges which ranges from competing with foreign-made products to bigger and smaller businesses owned by male entrepreneurs in their country. For them to remain in business despite these hitches, they need competencies that will enable them to present their goods and services to their customers at price that will yield better sales and profitability. In view of preceding discussion, Mitchemore et al. (2014) suggested that further studies need to be conducted on competencies of women entrepreneurs and its relationship with their business success. Therefore, the aims of this study are: To examine the effects of strategic, opportunity and organizing competencies on firm performance.

\section{LITERATURE REVIEW}

\subsection{Women Entrepreneurs in Nigeria}

According to Woldie and Adersua (2004) globally, the numbers of women entrepreneurs have increased and their impact is just beginning to be felt. The number of business owned by them continues to increase steadily worldwide. It was estimated that firms owned by women accounted for $25 \%$ to $33 \%$ of all businesses globally (National Foundation for Women Business Owners, 1998) as cited in Woldie and Adersua (2004). Report from World Bank Group (2013), shows that women contribution to economic growth and massive reduction of poverty around the world. In addition to this, the report also showed that in the United States, for example, women-owned firms are growing at more than double the rate compared to other firms, contributing nearly $\$ 3$ trillion to the economy and they created 23 million jobs. It was projected that in the year 2018, more that than half of 9.72 million new jobs that will be created in the US in SMEs sector will be created by SMEs owned by women (VanderBrug 2013).

The same situation exists in Nigeria. Dated back to the pre-colonial and post-colonial era, women dominated ownership of both wholesale and retail businesses in Nigeria (Aderemi, Ilori, Siyanbola, $\&$ Adegbite, 2008). Women entrepreneurs in Nigeria are major contributors to economic growth and they have generated employment to a teeming population (Iyiola \& Azuh, 2014). Evidence can be found in the report of the survey conducted by SMEDAN and National Bureau of Statistics (2013), which shows that women-owned business was able to generate 22,591,229 employments across Nigeria. Wholesale/retail businesses gained the highest portion of over 14 million which represent $62.66 \%$ of the total jobs generated by women entrepreneurs. Mining and quarrying produced the lowest rate of employment generation, where they generated barely 15 thousand jobs.

Women-owned businesses have been expanding to almost all the sectors of the economy. For instance, they are making progress towards establishing their presence in businesses in the formal sector and many businesses in the informal sector are owned by women. Their involvement in agricultural activities enables them to provide a sizable percentage of the labour force on the farm and they supplied domestic food in Nigeria. Ukonu and Tafamel (2011) stated that their entrepreneurial activities in both micro, small and medium scale production activities and their involvement in the formal/informal sector have added value to the economy of Nigeria. The social aspects of the women themselves and their immediate environment were not left out.

Therefore, it is obvious that women entrepreneurs in Nigeria are major contributors to the economy, as they strive to make a difference in the socio-economic arena. Their localities not only benefited from their numerous ideas, energy, and capital resources. They were also able to generate jobs as well as open more business opportunities for suppliers and other business chain (Iyiola \& Azuh, 2014). Empowering women economically in Nigeria is a key factor in improving the economy. This 
is one of the reasons for Nigeria to seek for more empowerment for women entrepreneurs to promote rapid economic development (Adetoyinbo, 2015).

\subsection{Entrepreneurial Competency}

Competency as a term has long been used in most management literature. It can be divided into two; that is natural and unnatural competence. Meutia and Ismail (2012) stated that natural competence consists of characteristic, attitude, self-image and social role. Unnatural or learned competence is skills that are needed when a task is done, which is acquired through practical and theoretical learning. This includes; skills, knowledge and experience. Therefore, entrepreneurial competencies are the underlying characteristics possessed by an individual which assist them to execute the tasks in a manner that is most befitting (Lazar \& Paul, 2015).

\subsubsection{Strategic Competency}

Strategic competency is related to setting, evaluating and implementing the strategies for the whole firm (Man, Lau, \& Chan, 2002). Ahmad, Ramayah, Wilson, and Kummerow (2010a) articulated strategic competency as the ability of the entrepreneur to monitor progress toward strategic goals, prioritise task to agree with business objectives, identify long-term issues, threats or opportunities, current actions to be in line with strategic goals, matched the outcome against strategic goals, redesign business to achieve long-term goals adequately, determine strategic actions through weighing costs and benefits. It is also, the ability to setup long term strategic plan that relates to the vision of the organization and also develops strategies that will enable the achievement of the plan (Stonehouse \& Pemberton, 2002).

\subsubsection{Opportunity Competency}

Among the central functions of the entrepreneurs, is to be able to identify and make the best use of business opportunities that can stimulate the performance of the firm. Opportunity competency comprises of the entrepreneurial activities in actively seeking new opportunities, identifying opportunities, and developing the opportunities (Seabela \& Fatoki, 2014). Hoyos-Ruperto, Romaguera, Carlsson, and Lyytinen (2013) stated that the positive perception of numerous opportunities available in the marketplace is one of the important conditions that are crucial to the success of the firm. It means that women entrepreneurs that want accelerated growth for their business should take possession of this type of competency with seriousness. If not her business will not experience growth as expected.

\subsubsection{Organizing Competency}

Organizing competency is the capacity of the entrepreneur to direct, lead, delegate, encourage, plan and schedule work, develop program and prepare the finances of the firm (Kaur \& Bains, 2013). This competency is related to managerial competency (Umeze \& Ohen, 2015). It involves managing both internal and external programs of the organization, for instance, promotion of firm's goods and services, proper financial management, logistics and management of human resources (Lans, Verstegen, \& Mulder, 2011; Wickramaratne, Kiminami, \& Yagi, 2014).

Furthermore, this competency also involves a process of breaking down the task into convenient obligations or duties, in which task will be grouped and qualified staff will be responsible for its execution as planned (UNESCO-Nigeria TVE, 2010). Thus, organizing competency will aid women entrepreneurs in the efficient coordination of all resources of their firms for optimum utilization. By ensuring that right thing is done at the right time by the right people. 


\subsection{Firm Performance}

In the field of strategic management, firm performance has been considered as one of the ultimate criterion variable (Aziz \& Mahmood, 2011). It is a central issue in business activities. Therefore, achieving it demand adequate and diligent planning and commitment (Shehu \& Mahmood, 2014). According to Oo (2013) firm performance could mean the success level of the business in the market within which it operates. Business performance can also be referred to as the yardstick use to quantify results achieved by the firm for a period (Sucipto, Oktaviani, \& Rizal, 2015). Whatever the definition adopted, as indicated by Trkman (2010) business performance evaluation is a critical issue. Hence the performance enables monitoring of either success or failure of the organization. Meanwhile, issues such as customer brand loyalty, an increase in the volume of sales, customer satisfaction, growth in market shares and adequate return on investment are integral components of firm performance (Morgan, 2012).

\subsection{Research Framework}

This research framework is proposed for empirical investigation of the relationship between the constructs.

\section{Entrepreneurial Competency}

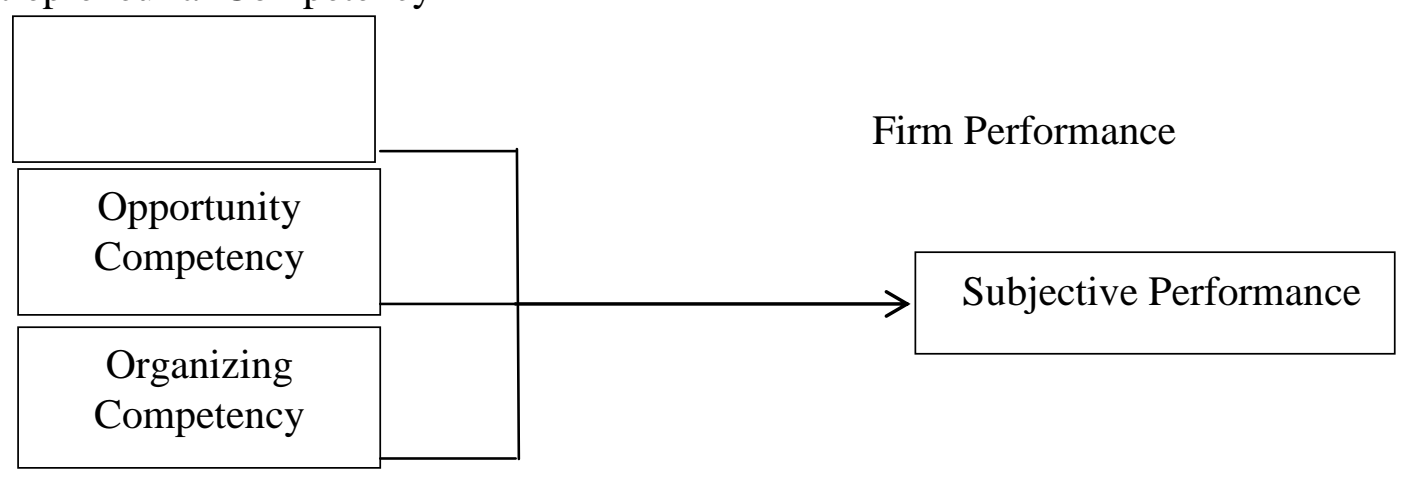

Figure 1 Research Framework (Variables adopted from Man, 2001; Ahmad, 2007)

For women entrepreneurs to achieve business success, acquiring and leveraging on their competencies is of critical importance. Competencies will enhance the competitiveness of their enterprises in the market (López-Gamero, Molina-Azorín, \& Claver-Cortes, 2009). Thus, resources and capabilities possessed by the entrepreneurs will provide them with the avenue to perform better than their competitors and achieve remarkable success in their business endeavours. Base on the foregoing discussion and research framework in figure 1, the following hypotheses were formulated:

H1: Strategic competency will have positive and significance effects on firm performance.

$\mathrm{H} 2$ : Opportunity competency will have positive and significance effects on firm performance.

H3: Organising competency will have positive and significance effects on firm performance.

\section{RESEARCH METHODS}

\subsection{Sample and Data Collection}

The sample of this study comprised of 200 women entrepreneurs. They are running various micro businesses in Kaduna state, Nigeria. Simple random sampling technique was adopted for this study. To obtain the 200 respondents, the process involves picking of pieces of paper in box, which 
contains the names of the women entrepreneurs, as provided by Small and Medium Enterprises Development Agency of Nigeria (SMEDAN) Kaduna state office. This process was done until 200 women entrepreneurs were picked. Thus, the data were collected using questionnaires.

\subsection{Survey Instrument}

Survey instrument used to measure entrepreneurial competencies such as strategic, opportunity and organizing competencies was extracted from the work of Man (2001). Each of the female entrepreneurs were requested to rate the items that best described the competencies they possessed. A five point Likert-scale was used. The ratings started from 1 strongly disagree to 5 strongly agree. Furthermore, survey instrument used for measuring firm performance was adopted form Chandler and Hanks (1993) . The rating was also based on five point Likert-scales, starting from $1=$ very dissatisfied to $5=$ very satisfied.

\section{RESULTS}

This section presents findings of this study. Two softwares were used, which comprised of Statistical Package for social sciences (SPSS) and Partial Least Square (SmartPLS) version 2.0. SPSS was used for data entry and purification. SmartPLS was used for higher statistical analysis. In this study, no case of missing data and extreme case of outlier was recorded.

The profiles of the respondents as showed in Table 1, revealed that majority of the respondents were 21 years and above. This means that, majority of women entrepreneurs are matured business owners. Although, many of the respondents' level of education are below university degree but they have been running their businesses for many years. They have considerable years of business experience which is useful for them in day to day running of their businesses.

\section{Table 1 The profile of the respondents}

\begin{tabular}{lcc}
\hline \multicolumn{1}{c}{ Description } & Frequency $(\mathrm{n}=200)$ & Percentage $(\%)$ \\
\hline Age & 53 & 26.5 \\
20 or below & 91 & 45.5 \\
$21-40$ & 56 & 28.0 \\
41 or above & & \\
Marital Status & 112 & 56.0 \\
Married & 61 & 30.5 \\
Single & 12 & 6.0 \\
Divorced & 15 & 7.5 \\
Widowed & & \\
Children & 130 & 65.0 \\
Yes & 70 & 35.0 \\
No & & \\
Years in the current business & 51 & 25.5 \\
5 years or below & 75 & 37.5 \\
6-10 years & 74 & 37.0 \\
11 years or above & & \\
Level of education & 36 & 18.0 \\
Secondary or lower & 48 & 24.0 \\
Diploma/NCE & 78 & 39.0 \\
HND/First degree & 32 & 16.0 \\
Post graduate & 6 & 3.0 \\
Others & & \\
\hline
\end{tabular}




\begin{tabular}{lll}
\hline Type of business & & \\
Service & 39 & 19.5 \\
Trade & 83 & 41.5 \\
Manufacturing & 54 & 27.0 \\
Agriculture & 24 & 12.0 \\
\hline
\end{tabular}

NCE $=$ National Certificate of Examination

HND = Higher National Diploma.

Furthermore, test for common method bias was conducted, because data for the constructs were gathered using the same questionnaire from a single respondent. Harman's single factor test was conducted to identify potential problem. The result showed that 7 distinct factors emerged which was responsible for $59.57 \%$ of variance from un-rotated factor analysis that used the Eigen-value greater that one criterion. The first factor only explains $24.23 \%$ of the variance. Hence no single dominant factor emerged. Therefore, common method bias can be concluded not to be an issue in the data collected for this study.

\subsection{Measurement Model Evaluation}

The measurement model evaluation of this study was done to determine the reliability of the items and construct validity. It is made-up of internal consistency reliability and constructs validity to establish items reliability and constructs' accuracy (Hair, Hult, Ringle, \& Sarstedt, 2014).

\subsubsection{Reliability Analysis}

In the evaluation of internal consistency reliability, outer loadings and their respective indicator reliability are presented to portray Composite Reliability. This is because, Composite reliability emphasises on individual item reliability which must be 0.5 or above (Hair et al., 2014). However, Hulland (1999) argue that indicator is said to be reliable if the value is 0.4 or above. The result of this study revealed that all indicators are reliable. Hence, the values were greater than 0.4 as recommended. Similarly, all composite reliability (CR) measurements are more than the cut-off values of 0.70 recommended by (Hair et al., 2014). This indicates that all the constructs are reliable as shown in Table 2.

\subsubsection{Construct Validity}

Convergent validity and discriminant validity are evaluated to indicate construct validity. While the convergent validity is examined through the outer loadings and AVE. Discriminant Validity is examined through Fornell-Larcker criterion.

\subsubsection{Convergent Validity}

Hair, Black, Babin, and Anderson (2010) argue that, 0.6 or higher is the minimum outer loading coefficient in a measurement model. Hair et al. (2014) suggested 0.70 or higher as minimum outer loading. Furthermore, Hair et al. (2014) suggested an AVE value of 0.50 or above shows that, on average, the variable explains more than half of the variance of its indicators. Table 2 showed that, all the outer loadings are above 0.60 while the (AVE) have achieved 0.50 and above.

Table 2 Parameter Estimates of the Measurement Model

\begin{tabular}{cccccc}
\hline LV & MV & $\begin{array}{c}\text { Outer } \\
\text { Loadings }\end{array}$ & IR & CR & AVE \\
\hline STRCOM & STRCOM2 & 0.683 & 0.466 & 0.828 & 0.547 \\
\hline
\end{tabular}




\begin{tabular}{llllll}
\hline & STRCOM3 & 0.704 & 0.496 & & \\
STRCOM5 & 0.778 & 0.605 & & \\
OPPCOM & STRCOM6 & 0.789 & 0.623 & & \\
ORGCOM & OPPCOM1 & 0.920 & 0.846 & 0.819 & 0.696 \\
& OPPCOM3 & 0.738 & 0.545 & & \\
& ORGCOM1 & 0.731 & 0.534 & 0.891 & 0.540 \\
& ORGCOM2 & 0.790 & 0.624 & & \\
& ORGCOM3 & 0.794 & 0.630 & & \\
& ORGCOM4 & 0.684 & 0.468 & & \\
& ORGCOM5 & 0.753 & 0.567 & & \\
& ORGCOM6 & 0.714 & 0.510 & & \\
& ORGCOM7 & 0.666 & 0.444 & & \\
& FIRMPER2 & 0.698 & 0.487 & 0.843 & \\
& FIRMPER4 & 0.632 & 0.399 & & \\
& FIRMPER5 & 0.718 & 0.516 & & \\
& FIRMPER6 & 0.758 & 0.575 & & \\
& FIRMPER7 & 0.787 & 0.619 & & \\
\hline
\end{tabular}

$\mathbf{L V}=$ latent variable, $\mathbf{M V}=$ Manifest variable, $\mathbf{C R}=$ Composite Reliability, $\mathbf{A V E}=$ Average Variance Extracted, IR = Indicator Reliability. (Result extracted from PLS2.0 software)

\subsubsection{Discriminant Validity}

It means that, a variable is unique and captures phenomena not represented by other varying constructs in the model. The most popular method used in determining discriminant validity of construct is Fornell-Larcker criterion. It indicated that square root of AVE of each variable greater than the correlation for each construct. The figures in bold in Table 3 are all greater than each of the coefficients on which they have been placed. This indicates that, a Discriminant Validity of constructs has been achieved (Hair et al., 2014). The result of discriminant validity is present in Table 3.

Table 3 Discriminant validity of construct Fornell-Larcker criterion

\begin{tabular}{ccccc}
\hline & FIRMPER & OPPCOM & ORGCOM & STRCOM \\
\hline FIRMPER & $\mathbf{0 . 7 2 0}$ & & & \\
OPPCOM & 0.338 & $\mathbf{0 . 8 3 4}$ & & \\
ORGCOM & 0.384 & 0.265 & $\mathbf{0 . 7 3 5}$ & \\
STRCOM & 0.388 & 0.345 & 0.385 & $\mathbf{0 . 7 4 0}$ \\
\hline
\end{tabular}

FIRMPER = Firm performance, OPPCOM = Opportunity competency, ORGCOM = Organising competency, STRCOM = Strategic competency. (Result extracted from PLS2.0 software)

\subsection{Structural Model Evaluation}

The paths of the relationship between the independent and dependent variables were computed in the structural model and bootstrap analysis was done to evaluate the statistical significance of the path coefficient. The significance levels were set at $\mathrm{p}<.10 \mathrm{p}<.05$ and $\mathrm{p}<.01$. The critical values are $1.65,1.96$ and 2.57 . The confidence levels are taking at $90 \%, 95 \%$ and $99 \%$ respectively. The 500 bootstrapping depicting coefficients for the paths regression effects is presented in figure 2. 


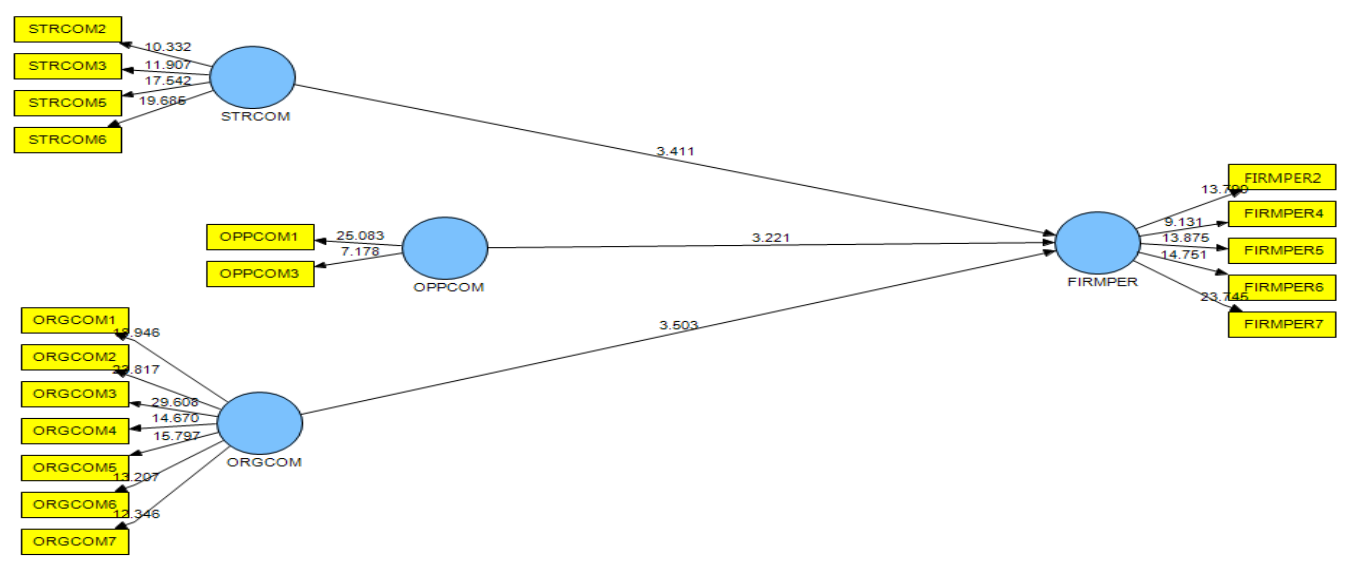

Figure 2 PLS 500 Bootstrap Graph (Extracted from PLS2.0 software)

STRCOM = Strategic competency, OPPCOM = Opportunity competency, ORGCOM = Organising competency, FIRMPER = Firm performance.

From the regression results all the three constructs of independent variables were positively and significantly related to firm performance. Strategic competency (STRCOM) with $(\beta=0.227, t=$ $3.411, \mathrm{p}<0.01)$ has a direct positive and significance effect on firm performance (FIRMPER). Opportunity competency (OPPCOM) with $(\beta=0.195, t=3.221, \mathrm{p}<0.01)$ has a direct positive and significance effect on firm performance (FIRMPER). Similarly, organizing competency (ORGCOM) with $(\beta=0.245, t=3.503, \mathrm{p}<0.01)$ has a direct positive and significance effect on firm performance (FIRMPER). Therefore, hypotheses $\mathrm{H} 1, \mathrm{H} 2$ and $\mathrm{H} 3$ of this study were all supported. Table 4 shows the statistical detail of parameter estimates of direct effect relationships for this study.

\section{Table 4 Parameter Estimates of Direct Effect Relationships}

\begin{tabular}{ccccccc}
\hline Hypotheses & Path & B & SE & $P$ value & $t$ value & Decision \\
\hline H1 & STRCOM -> FIRMPER & 0.227 & 0.066 & 0.000 & $3.411^{* * * *}$ & Supported \\
H2 & OPPCOM -> FIRMPER & 0.195 & 0.061 & 0.000 & $3.221^{* * * *}$ & Supported \\
H3 & ORGCOM -> FIRMPER & 0.245 & 0.070 & 0.000 & $3.503^{* * *}$ & Supported
\end{tabular}

***significant at $\mathrm{p}<0.01$, **significant at $\mathrm{p}<0.05$, *significant at $\mathrm{p}<0.10$, All hypotheses are one tailed. (Result extracted from PLS2.0 software)

\subsection{Coefficient of Determination $\left(\mathbf{R}^{2}\right)$}

As a degree of model's predictive accuracy, $\mathrm{R}^{2}$ represents the exogenous constructs' combined effects on the endogenous construct. Scholarly researches consider 0.67, 0.33 and 0.19 as substantial, moderate and weak respectively (Chin, 1998). In this structural model, the three exogenous variables; strategic competency (STRCOM), opportunity competency (OPPCOM) and organizing competency (ORGCOM) explained $25 \%$ of the variance in firm performance (FIRMPER) as dependent variable. The Coefficient of Determination $\left(\mathrm{R}^{2}\right)$ for this study is considered weak.

\subsection{Effect Size $\left(f^{2}\right)$}

This is an evaluation of fundamental impact of exogenous variables on the endogenous variable when the former is omitted from the model. Chin (2010) stated that, in social science researches, $2 \%$ effect sizes are small but acceptable, 5-10\% moderate, while $11 \%$ and above are substantial. 
Paterson, Harms, Steel, and Credé (2016) stated that, based on the opinion of Cohen, lots of effects in the social sciences are mostly small, but acceptable. The effect size $\mathrm{f}^{2}$ was determined using this formula:

$f^{2}=\underline{\mathrm{R}^{2} \text { inclusive }-\mathrm{R}^{2} \text { exclusive }}$

$1-\mathrm{R}^{2}$ inclusive

where;

$\mathrm{R}^{2}$ inclusive $=$ Variance explained coefficient when the variable is included in the model.

$\mathrm{R}^{2}$ exclusive $=$ Variance explained coefficient when the variable is excluded.

$1=$ constant

The effect size as presented in Table 5 consist of STRCOM (0.054), OPPCOM (0.038) and ORGCOM (0.062). The result of the interaction between the independent variables and dependent variable indicated that the effect of strategic and organizing competency on firm performance are moderate but effect of opportunity competency is small on firm performance. Therefore, all the three independent variables of this study have significant effect on the dependent variable.

Table 5 Effect Size $\left(\boldsymbol{f}^{2}\right)$

\begin{tabular}{lcccl}
\hline Variable & $\mathrm{R}^{2}$ inclusive & $\mathrm{R}^{2}$ exclusive & Effect $\left(f^{2}\right)$ & Size \\
\hline STRCOM & 0.248 & 0.207 & 0.054 & Moderate \\
OPPCOM & 0.248 & 0.219 & 0.038 & Small \\
ORGCOM & 0.248 & 0.201 & 0.062 & Moderate \\
\hline
\end{tabular}

STRCOM = Strategic competency, OPPCOM = Opportunity competency, ORGCOM = Organising competency.

\subsection{Predictive Relevance $\left(Q^{2}\right)$}

To obtain predictive relevance of exogenous variables on the endogenous variable, Cross-Validated Redundancy is used. Every dth data point in the construct 's indicators are omitted and evaluates the parameters with the remaining data points. The omission distance is usually chosen between 5 to 10. For this study 7 was chosen. Hair et al., (2014) stated that values greater than zero shows that exogenous constructs have predictive relevance for the endogenous construct. Table 6 presents the result of predictive relevance for this study. The table showed that all independent variables have predictive relevance on dependent variable. Hence, all $\mathrm{Q}^{2}$ have values $>0$.

\section{Table 6 Predictive relevance $\left(\mathbf{Q}^{2}\right)$}

\begin{tabular}{cc}
\hline Number of Rounds & $\begin{array}{c}\text { Endogenous variable } \\
\text { Firm Performance }\end{array}$ \\
\hline Case 1 & 0.159 \\
Case 2 & 0.124 \\
Case 3 & 0.042 \\
Case 4 & 0.111 \\
Case 5 & 0.145 \\
Case 6 & 0.092 \\
Case 7 & 0.127 \\
\hline
\end{tabular}

All cases were obtained by 1 - SSE/SSO using blindfolding technique.

SSE $=$ Sum of Square Error. SSO = Sum of Square Observation. (Result extracted from PLS2.0 software) 


\section{DISCUSSION}

The result of this study proved that entrepreneurial competency plays a significant role in successes recorded by the Nigeria women entrepreneurs. Their competency enables them to triumph in the market despite stiff competition in their respective business environment.

In one hand, the result obtained in this study agrees with the result of the study conducted by some of the previous researchers. On the other hand, it did not concur with others. For instance, the study conducted by Man, Lau, \& Snape, (2008) indicated that there is a direct relationship between strategic competency and business performance especially when investment efficiency was used to evaluate the performance of the firm. Study conducted by conducted by Man and Lau (2005) revealed that business entrepreneurs Hong Kong ranked low in strategic competency. They claimed that scope of their business is low, they don't need strategic competency.

However, the results of this study proved that it is of utmost importance for business owners to have long term and comprehensive plan for the business. Plans and its resultant execution cannot be achieved without possession of competencies. Hence, strategic competency possessed by women entrepreneurs in Nigeria enables them to take their business forward.

Similarly, opportunity competency is considered as one of the most distinctive competencies for the business owners. Business opportunities are those needs and want of the customers to be satisfied. It is not every business opportunity that is profitable. They must be evaluated before investing in it. The result obtained in this study shows that women entrepreneurs in Nigeria can actively search and make fortuitous discovery of business opportunities. They understood that discovery of profitable business opportunities will provide avenue for their business to achieve success. Thus, opportunity competency encouraged women entrepreneurs in Nigeria to take considerable risks which eventually turn out to be a profitable business venture.

Furthermore, the result of this study proved that organizing competency has the capacity to improve the performance of a business firm. This is similar to study conducted by Ahmad (2007) who indicated that those entrepreneurs in Australia and Malaysia spend most of their time in planning and organizing human and other physical resources of their firms. They understood that without organizing these resources, business success will be far away from them. Women entrepreneurs in Nigeria also took their time to ensure that they organised their resources, they delegate task effectively and motive one or few staff working with them. Through this, performance of their firm was enhanced. Efficient coordination of the little resource in the disposal of entrepreneur successes can be achieved. Therefore, the results obtained from this study proved that entrepreneurial competencies such as strategic, opportunity and organizing competencies can influence the success of firms owned by women entrepreneurs in Nigeria.

\section{CONCLUSION}

In any profit-making firm, the owner of such business is the most vital element. The owner is the one responsible for the provision of all necessary resources needed for day to day running of the business to achieve success. They also have in their mind where they want the business to be in the future, which will be made known to their employees and subordinates. Therefore, for women entrepreneurs in Nigeria acquiring and implementing competencies has become very crucial. The confirmation obtained from this study proved the link between competencies of women entrepreneurs and success of their firms. To this end, government of Nigeria and other stakeholders need to focus their attention on issues that is related to entrepreneurial development of women such as, giving them qualitative training and retraining, provision of loan facilities at a low interest. The 
women entrepreneurs have the potential to contribute to economic development of Nigeria via job creation and poverty alleviation.

It is therefore, recommended that future research need to focus on women entrepreneurs in informal sector, hence this study questionnaires were administered to women entrepreneurs in formal sector. Mixed method research approach can also be conducted for more understanding of competencies of women entrepreneurs, its interaction and deployment to improve performance of their businesses.

\section{REFERENCES}

Aderemi, H., Ilori, M., Siyanbola, W., \& Adegbite, S. A. 2008. An assessment of the choice and performance of women entrepreneurs in technological and non-technological enterprises in southwestern Nigeria. African Journal of Business Management, 2(10), 165.

Adesua-Lincoln, A. 2012. Nature of leadership practices of Nigerian female entrepreneurs. International Journal of Business and Social Science, 3(10): 50-59.

Adetoyinbo, B. 2015. Nigeria: Women outnumber men in business startups. Harambee Today. Ahmad, N. H. 2007. A cross-cultural study of entrepreneurial competencies and entrepreneurial success in SMEs in Australia and Malaysia. (thesis), University of Adelaide Australia.

Ahmad, N. H., T. Ramayah, C. Wilson, and L. Kummerow. Is entrepreneurial competency and business success relationship contingent upon business environment? A study of Malaysian SMEs. International Journal of Entrepreneurial Behavior \& Research, 2010, 16(3): 182-203.

Aziz, S. A., and R. Mahmood. 2011. The relationship between business model and performance of manufacturing small and medium enterprises in Malaysia. African Journal of Business Management, 5(22): 8918.

Brinckmann, J. 2008. Competence of top management teams and success of new technology-based firms: Springers.

Chandler, G. N., and S.H. Hanks. 1993. Measuring the performance of emerging businesses: A validation study. Journal of Business Venturing, 8(5), 391-408.

Chin, W. W. 1998. The partial least squares approach to structural equation modeling. Modern methods for business research, 295(2), 295-336.

Chin, W. W. 2010. How to write up and report PLS analyses Handbook of partial least squares (pp. 655-690): Springer.

Cohoon, J. M., V. Wadhwa and L. Mitchell. 2010. The Anatomy of an Entrepreneur: Are

Successful Women Entrepreneurs Different from Men? Ewing Marion Kauffman Foundation, Available at SSRN: https://ssrn.com/abstract=1604653 or http://dx.doi.org/10.2139/ssrn.1604653

Hair, J. F., W.C. Black, B.J. Babin, and R.E. Anderson. 2010. Multivariate data analysis. Upper

Saddle River, New Jersey.

Hair, J. F., G. T. M., Hult, C. M., Ringle and M. Sarstedt. 2014. A Premier on Partial Least Squares Structural Equation Modelling (PLS-SEM). United States of America.

Hoyos-Ruperto, M. D., J.M Romaguera, B. Carlsson, and K. Lyytinen 2013. Networking: A critical success factor for entrepreneurship. American Journal of Management, 13(2): 55-72.

Hulland, J. 1999. Use of partial least squares (PLS) in strategic management research: A review of four recent studies. Strategic Management Journal, 20(2): 195-204.

Iyiola, O., \& Azuh, D. 2014. Women Entrepreneurs as Small-Medium Enterprise (SME)

Operators and their Roles in Socio-Economic Development in Ota, Nigeria. International Journal of Economics, Business and Finance, 2(1), 1-10.

Kaur, H., and A. Bains. 2013. Understanding the concept of entrepreneur competency. Journal of Business Management \& Social Sciences Research, 2(11): 31-33.

Kiggundu, M. N. 2002. Entrepreneurs and entrepreneurship in Africa: What is known and what needs to be done. Journal of developmental entrepreneurship, 7(3): 239.

Lans, T., J. Verstegen, and M. Mulder 2011. Analysing, pursuing and networking: Towards a 
validated three-factor framework for entrepreneurial competence from a small firm perspective. International Small Business Journal, 29(6): 695-713.

Lazar, N., and G. Paul. 2015. Entrepreneurial competencies in a business enterprise - An overview. International Journal of Scientific Research, 4(1): 226-227.

López-Gamero, M. D., J. F., Molina-Azorín, and E. Claver-Cortes 2009. The whole relationship between environmental variables and firm performance: Competitive advantage and firm resources as mediator variables. Journal of environmental management, 90(10): 3110-3121.

Man, T. W., and T. Lau. 2005. The context of entrepreneurship in Hong Kong: An investigation through the patterns of entrepreneurial competencies in contrasting industrial environments. Journal of Small Business and Enterprise Development, 12(4): 464-481.

Man, T. W., T., Lau, and K. Chan 2002. The competitiveness of small and medium enterprises: A conceptualization with focus on entrepreneurial competencies. Journal of Business Venturing, 17(2): 123-142.

Man, T. W., T. Lau, and E. Snape 2008. Entrepreneurial competencies and the performance of small and medium enterprises: an investigation through a framework of competitiveness. Journal of Small Business \& Entrepreneurship, 21(3): 257-276.

Man, W.-y. T. 2001. Entrepreneurial competencies and the performance of small and medium enterprises in the Hong Kong services sector. Unpulished PhD Dissertation, the Hong Kong Polytechnic University.

Meutia, and T. Ismail. 2012. The development of entrepreneurial social competence and business network to improve competitive advantage and business performance of small medium sized enterprises: a case study of batik industry in Indonesia. Procedia-Social and Behavioral Sciences, 65: 46-51.

Mitchelmore, S., and J. Rowley. 2010. Entrepreneurial competencies: a literature review and development agenda. International Journal of Entrepreneurial Behavior \& Research, 16(2): 92111.

Mitchelmore, S., and J. Rowley. 2013. Entrepreneurial competencies of women entrepreneurs pursuing business growth. Journal of Small Business and Enterprise Development, 20(1): 125-142. Mitchelmore, S., J. Rowley, and E. Shiu. 2008. Competencies associated with growth of women-led SMEs. Journal of Small Business and Enterprise Development, 21(4): 588-601. Mitchelmore, S., J. Rowley, and E. Shiu. 2014. Competencies associated with growth of womenled SMEs. Journal of Small Business and Enterprise Development, 21(4), 588-601.

Morgan, N. A. 2012. Marketing and business performance. Journal of the Academy of Marketing Science, 40(1): 102-119.

Oo, H. M. 2013. Determinants of SMEs' Performance: The Case of Kyaing Tong, Eastern Shan State, Myanmar. AU-GSB e-JOURNAL, 6(2).

Paterson, T. A., P. Harms, P. Steel, and M. Credé. 2016. An assessment of the magnitude of effect sizes evidence from 30 years of meta-analysis in management. Journal of Leadership \& Organizational Studies, 23(1): 66-81.

Seabela, M., and O. Fatoki. 2014. The entrepreneurial competencies of non-business university students in South Africa. International Journal of Educational Research, 6(3): 375-381.

Shehu, A. M., and R. Mahmood. 2014. The relationship between market orientation and business performance of Nigerian SMEs: The role of organizational culture. International Journal of Business and Social Science, 9(1): 159-168.

SMEDAN, \& National Bureau of Statistics. 2013. Collaborative survey: selected findings. Nigeria.

Stonehouse, G., and J. Pemberton. 2002. Strategic planning in SMEs-some empirical findings. Management Decision, 40(9): 853-861.

Sucipto, E., Oktaviani, R., \& Rizal, R. 2015. The effects of partnership and entrepreneurship toward business performance of oyster mushroom (pleurotusostreatus). Indonesian Journal of Business and Entrepreneurship (IJBE), 1(1), 32-41.

Trkman, P. 2010. The critical success factors of business process management. International 
journal of information management, 30(2): 125-134.

Ukonu, O. I., \& A. E. Tafamel. 2011. Problems, challenges and prospects of female entrepreneurs in Gwagwalada, Abuja. African Research Review, 5(3).

Umeze, G. E., and S.B. Ohen. 2015. Marketing Mix Strategies and Entrepreneurial Competence: Evidence from Micro Restaurants in Calabar Metropolis, Cross River State, Nigeria. Paper presented at the 2015 Conference, August 9-14, 2015, Milan, Italy.

UNESCO-Nigeria TVE. 2010. Instructional/Teaching Material. Nigeria: National Board for

Technical Education.

VanderBrug, J. 2013. The global rise of female entrepreneurs. Harvard Business Review.

Wickramaratne, A., A. Kiminami, and H. Yagi. 2014. Entrepreneurial competencies and entrepreneurial orientation of tea manufacturing firms in Sri Lanka. Asian Social Science, 2014, 10(18): 50.

Woldie, A., \& A. Adersua. 2004. Female entrepreneurs in a transitional economy: Businesswomen in Nigeria. International Journal of Social Economics, 31(1/2), 78-93.

World Bank Group. 2013. Female entrepreneurship resource point - Introduction and module 1:

Why gender matters. Retrieved from http://www.worldbank.org/en/topic/gender/publication/female-entrepreneurship-resource-pointintroduction-and-module-1-why-gender-matters. 